\title{
Effect of tomatoes on the prevention of cardiovascular diseases
}

\author{
Marina Palff*, Helena Tomić-Obrdalj \\ Podravka d.d., Koprivnica, Croatia
}

Tomato (Solanum lycopersicum L.) is an important ingredient in the Mediterranean diet. Studies have shown that this particular type of diet has a very positive effect on human health, including cardiovascular health. ${ }^{1}$ Tomatoes are a significant source of nutrients such as lycopene, beta-carotene, folate, potassium, vitamin $\mathrm{C}$, flavonoids and vitamin $\mathrm{E}$. Carotenoid lycopene is highly represented, which is a very powerful antioxidant due to its chemical structure. The nutrients in tomatoes may have a favorable effect on lipid profile, homocysteine, platelet aggregation and blood pressure. ${ }^{2}$

The Women' Health Study (WHS) conducted in the United States over seven years period showed the potential effect of tomatoes on women's health. The study involved nearly 40,000 middle-aged women who were not initially diagnosed with cancer or cardiovascular disease. The results sug-

Received: $29^{\text {th }}$ Apr 2014

*Address for correspondence: Podravka d.d., Ante Starčevića 32, HR-48000 Koprivnica, Croatia.

Phone: +385-48-651-617

Fax:++385-48-651-941

E-mail: marina.palfi@podravka.hr gest that consumption of $\geq 7$ servings of tomato products per week reduce the risk of cardiovascular disease by nearly $30 \%$ compared to consuming $<1.5$ servings/wk. Particularly significant impact on the vascular events, myocardial infarction and stroke was noticed in people who consumed $\geq 10$ servings of tomato products per week. ${ }^{3}$ Research of raw tomato consumption have shown beneficial effect on HDL cholesterol in over-weight women. ${ }^{4}$ Processed tomato compared to raw tomato shows better antiplatelet activity, most likely due to a higher content of components which have a positive impact on human health and can be used as an ingredient in functional food. ${ }^{5}$ Since tomato is known for its high amount of potassium, the consumption of this vegetable should be limited to people with renal failure or hyperkalemia.

Due to the valuable components, tomatoes and tomato products should be included in the daily diet of cardiac patients. Clinical studies focusing on determining the effect of tomatoes on the prevention of cardiovascular disease will continue.

KEYWORDS: tomato, lycopene, antioxidant, cardiovascular disease.

CITATION: Cardiol Croat. 2014;9(5-6):253.

\section{Literature}

1. Demarin V, Lisak M, Morović S. Mediterranean diet in healthy lifestyle and prevention of stroke. Acta Clin Croat. 2011;50:67-77.

2. Willcox JK, Catiganani GL, Lazarus S. Tomatoes and cardiovascular health. Criti Rev Food Sci Nutr. 2003;43(1):1-18.

3. Sesso HD, Liu S, Gaziano JM, Buring JE. Dietary lycopene, tomato-based food products and cardiovascular disease in women. J Nutr. 2003;133:2336-41.

4. Cuevas-Ramos D, Almeda-Valdés P, Chavez-Manzanera E, et al. Effect of tomato consumption on high-density lipoprotein cholesterol level: a randomized, single-blinded, controlled clinical trial. Diabetes Metab Syndr Obes. 2013;6:263-73.

5. Fuentes E, Forero-Doria O, Carrasco G, et al. Effect of tomato industrial processing on phenolic profile and antiplatelet activity. Molecules. 2013;18:11526-36. 